DOI 10.37882/2500-3682.2021.07.14

\title{
МЕХАНИЗМ РЕАЛИЗАЦИИ ДУХОВНОГО ПОТЕНЦИАЛА КАК ВОЗМОЖНОСТЬ ДУХОВНО-НРАВСТВЕННОГО РОСТА В ЮНОСТИ
}

\section{MECHANISM OF REALIZATION OF SPIRITUAL POTENTIAL AS A POSSIBILITY OF SPIRITUAL AND MORAL GROWTH IN YOUTH}

N. Trofimova

Summary: The article presents methodological developments of the concept of «spiritual potential». In particular, the mechanisms of realization of spiritual potential in youth are considered, taking into account the age characteristics of this period of ontogenesis. The article reveals the essence of the psychological mechanism of spiritual potential, as an integral interaction of psychological links that ensure the accumulation, exhaustion and at the same time the endless spiritual and moral resource of the individual. The question of the emergence of lack of spirituality and immorality in the modern world is considered.

Keywords: spiritual potential, mechanisms of spiritual potential, youth, spiritual and moral growth, spiritual experience, lack of spirituality, immorality.
Ю ношеский возраст в отношении развития духовного начала в человеке - универсальный в силу того, что для развития его личности можно получить достаточно целостную и динамическую картину всех граней духовно-душевной жизни человека. Например, развитие высших духовных ценностей добра, истины, красоты, которые содержат ощутимый трансцендентный фактор, может служить инструментом раскрытия и актуализации духовного потенциала человека. «Открываемое при этом высшее предназначение человека определяет смысл жизни и сопровождается переживаниями, которые могут проявляться в единстве таких граней, как интуиция, вдохновение, воодушевление, откровение, покаяние, прощение, просветление, благодать. Креативный заряд такого спектра состояний имеет для человека стратегический долговременный эффект, прочувствованный „каждой клеточкой тела”, оставляет о себе долгую память» [1].

Концепция целостной психологической структуры человека может служить базисом для формирования психологического механизма духовного потенциала личности юноши. Вместе с тем, данная концепция опирается на принцип развития, являющийся одним из основополагающих принципов в психологии. В настоящее

\author{
Трофимова Наталья Борисовна \\ Д.nсх.н., профессор, Воронежский государственный \\ педагогический университет \\ n_trofimova@mail.ru
}

Аннотация: В статье приводятся методологические разработки понятия «духовный потенциал». В частности, рассматриваются механизмы реализации духовного потенциала в юности с учетом возрастных особенностей данного периода онтогенеза. Раскрывается сущность психологического механизма духовного потенциала, как интегральное взаимодействие психологических звеньев, которые обеспечивают накопление, исчерпание и одновременно нескончаемость духовно-нравственного ресурса личности. Рассматривается вопрос появление бездуховности и безнравственности в современном мире.

Ключевые слова: духовный потенциал, механизмы духовного потенциала, юность, духовно-нравственный рост, духовный опыт, бездуховность, безнравственность. время имеет место тенденция к сближению принципа развития с системным подходом. Развитие рассматривается как вид необратимых изменений, которые характерны также и для системных объектов, «эволюция которых представляет собой закономерное усложнение их системной организации» [2].

Личность - это системная категория, имеющая множественную и разноуровневую детерминацию. Однако, говоря о структуре духовного потенциала юноши, необходимо учитывать тот факт, что «человек развивается в направлении возрастающей сложности; наша судьба неуклонно становиться все более уникальными и все более интегрированными с Иным: другими людьми, идеями, ценностями, тем, что вне нас» [7]. Для достижения состояния устойчивости рассматриваемой системы необходима постоянная компенсация регресса. Учеными (О.К. Тихомировым, В.Е. Клочко и др.) было обнаружено, что каждое изменение состояния человека сопровождается трансформацией окружающей его среды, изменением ценностно-смысловой структуры. Сотрудниками научной школы О.К. Тихомирова было доказано, что «объективная среда» приспосабливается к человеку ничуть не меньше, чем он к ней. «Элементы структурируемой ситуации приобретают различный смысл и цен- 
ность для субъекта, и эти неформальные компоненты возникают как результат соотнесения имеющегося у субъекта опыта (знаний, способов и т.д.) и конкретной ситуации» [2].

В случае соответствия опыта и ситуации у человека возникает состояние «напряженной возможности», которое появляется непосредственно тогда, когда происходит компенсация регресса, привносящего сбой в процесс развития. Возникающее состояние «напряженной возможности» для личности всегда энергозатратно. Вместе с тем, оно обеспечивает устойчивость и равновесие системы, которое, в свою очередь, обусловливает духовно-нравственную устойчивость личности. При этом меняющееся состояние человека изменяет состояния жизненного пространства, перестраивает ценностносмысловые координаты. В силу того, что смысл всегда связан с установкой, с готовностью реализовать определенное поведение по отношению к предмету, имеющему смысл, становится возможным движение системы по линии «духовная потребность - ситуация (осознанная необходимость) - накопление духовного опыта», это непосредственно отражает вектор развития личности в юности.

Несомненно, в юности человек обладает разной готовностью к реализации имеющегося духовного потенциала, у него определяются разные проявления духовно-нравственных качеств и разные способы компенсации регресса.

Основным принципом развития духовного потенциала в юности выступает положение, в соответствии с которым при освоении нравственного опыта и условий осуществляется трансформация абстрактной возможности обладания нравственным статусом, функциями, качествами в реальную возможность и превращение последней в действительность как результат, совокупность всех реализованных духовных, нравственных возможностей, предоставляемых подрастающему поколению.

Для процесса реализации духовного потенциала в юности необходим особый психологический механизм, который не сводится к механизму достижения цели деятельности или получения желаемого результата. При рассмотрении духовного потенциала как ресурса нравственных сил, он существенно отличается от имеющихся компетенций, сложившихся навыков и умений, а также запаса социального опыта. Можно утверждать, что духовный потенциал является тем «психологическим заместителем» знаний, компетенции и опыта, который начинает играть свою роль при отсутствии последних. Согласно воззрениям А.Н. Леонтьева, механизм деятельности обязательно включает в качестве существенного компонента навыки и умения, а вот механизм духовного потенциала активизирует принципиально иные звенья, обеспечивающие высокий уровень целедостижения даже в условиях недостаточного опыта или наличных знаний. Психологическая сущность духовного потенциала заключается в том, что он относится к затратному механизму осуществления деятельности, в то время как все другие известные механизмы овладения деятельностью и, прежде всего, механизм ее автоматизации предусматривают сбережение энергии. Без реализации механизма духовного потенциала невозможны такие явления, как самоотверженность, самопожертвование, самореализация и в крайних случаях выгорание личности.

Раскрывая сущность психологического механизма духовного потенциала, можно предположить, что он выступает как интегральное взаимодействие таких психологических звеньев, которые обеспечивают накопление, исчерпание и одновременно нескончаемость духовно-нравственного ресурса личности в таких обстоятельствах, которые требуют деятельности за пределом мыслимых ресурсов. В качестве примера таких ситуаций могут служить подвиги, бескорыстное самопожертвование, полная самоотдача в выполнении миссии с риском для жизни и др. Подобный механизм может действовать, если он содержит следующие звенья: накопление духовного опыта; формализация духовного опыта; развитие убеждений; систематизация мировоззрения; противопоставление идей; идеализация личностей и поступков; диссеминация, то есть распространение защищаемых идей [5].

Накопление духовного опыта выступает как начальное звено механизма реализации духовного потенциала личности в юности. На данном этапе необходимы реальные жизненные примеры духовной самореализации, саморазвития человека, которые послужили бы убедительным основанием для подражания.

В качестве примера, предлагаем рассмотреть категорию «русского героизма», с помощью которого мы формируем чувство гордости за свою страну, свой народ, свою нацию, за достижения и открытия, сделанные русским народом, за силу характера, за интернационализм русских, за великое историческое прошлое, за всю историю России, за культуру и духовность, за богатство русской души. Русский человек выступает при этом одной из главных ценностей, как покровитель традиционного русского образа, как защитник от нападок антирусских проявлений со стороны СМИ, старых и новых недругов России. Мы провели анкетирование старших школьников из пяти различных школ г. Воронежа (всего 550 человек). Показательно, что на вопрос: «Каким вы видите русского человека, назовите типичную черту его национального характера» - только $72 \%$ респондентов дали положительную характеристику, называя черту характера русского человека (душевность, бескорыстие, человечность, сила характера, терпение, щедрость, широта 
души, доброта и т.д.), остальные респонденты - 28\% на первое место поставили отрицательные характеристики, такие как: грубость, безалаберность, безответственность, пьянство и алкоголизм, жестокость и т.д. Характерно, что большинство негативных характеристик давали ребята другой национальности (20\%), хотя постоянно живут в России, а 8\% были русскими. Это значит, что эта группа русских школьников не испытывают гордости за то, что они - русские, а испытывают негативные переживания факта принадлежности к своему этносу. Школьники других национальностей (20\%) отражают социокультурную ситуацию в России, когда, прежде всего, русский человек забывает о своей культуре, её своеобразии и особенности. Известно, что по теории экспектаций, человек строит свое поведение в соответствии с ожиданиями окружающих, это наиболее ярко проявляется в школьном возрасте, закрепляясь в дальнейшем в устойчивое поведение и отношение, отражающееся на адаптации молодых людей [5].

В процессе онтогенетического развития происходит постоянное изменение человека, его нравственное формирование в период юности связано с накоплением духовного опыта и если юноше удастся достичь духовного роста во всех жизненно важных для него сферах, то можно утверждать, что нравственное изменение самого себя будет успешным.

Кроме того, накопление потенциала осуществляется за счет возможностей достижения личностью гармонизирующих резонансных отношений с обществом, характеризующих духовными эталонами, нравственными целями и этическими смыслами. При этом происходит не простое механическое накопление, а ориентация своего поведения на духовные ценности, на людей, чья жизненная позиция может стать примером духовного опыта.

Духовный опыт - понятие очень емкое, и основной единицей в нем выступает опыт нравственного поведения, как содержание и условие реализации способа действий и поступков. Нравственный опыт составляет целую систему зависимостей между отдельными его частями. Подрастающее поколение не формирует новый опыт нравственного поведения, а усваивает тот, который накоплен предшествующими поколениями. Однако усвоение опыта осуществляется активным путем, в связи с чем в него всегда привносится новое. При этом активная позиция самого человека является непременным условием духовного роста и усвоения нравственного опыта.

Однако личность в современном обществе может столкнуться с противоречием между естественным стремлением человека к духовному обогащению и теми социально обусловленными ценностями, которые определяют развитие конкретной личности. В этом случае компенсации регресса не происходит и можно наблю- дать не накопление, а снижение духовного потенциала до его минимального значения - состояния бездуховности. Социальные источники юношеской бездуховности надо искать там, где нет точек соприкосновения между обыденным и возвышенным в жизни (рассогласование опыта и ситуации). С бездуховностью непосредственно связана безнравственность как отсутствие святынь, авторитетов, идеалов и норм жизни.

Почему сегодня мы очень часто сталкиваемся с человеческим злом, безнравственностью, бездуховностью, жестокостью, девичьей агрессией, хамством, неуважением старших, издевательствами над слабыми и т.п.? Один из возможных вариантов ответа кроется в особенностях новой ситуации развития общества эпохе постмодерна, сформировавшей новую мировоззренческую установку: «все дозволено», «каждый прав по-своему», «учитель оказывает образовательные услуги», «нравственным быть - себе дороже» и т.п. Такая ситуация позволяет оправдать любой порок, провоцирует порождение пустоты, наполнением которой будут беспринципность, безнравственность, бесцельность, тотальное развращение и нравственная деградация молодежи. Самое неприятное, что эти проявления поддерживаются законом, превращаясь тем самым в норму. При этом духовная опустошенность наступает именно как пик такого наполнения.

Появление бездуховности и безнравственности может базироваться на личностных особенностях каждого человека. Духовно-нравственная составляющая личности позволяет овладеть способами саморазвития и самосовершенствования, чем ярче выражена эта составляющая, тем, легче справиться с некоторыми отрицательными особенностями личности, уметь противостоять безнравственности. При этом духовность придает смысл жизни, в нем человек ищет и находит ответы на вопросы: зачем он живет, каково его назначение в жизни, что есть добро и зло, истина и заблуждение, красивое и безобразное и т.п.

Способы поведения идут вразрез с установленными нормами в том случае, если они усвоены формально и юноша не находит идеала в тех лицах, которые их преподносят, а потребности и мотивы длительное время не удовлетворяются. В целом нравственное поведение школьников определяется его психологической установкой, которая детерминируется духовными потребностями и ситуациями. При этом накопленный духовный опыт становится более действенным в развитии духовного потенциала, если приобретает форму четких психологических установок, некритично воспринимающихся личностью в виде их одобрения в социуме [5].

Развитие духовного потенциала личности - это глубокая внутренняя борьба положительного с отрица- 
тельным, прекрасного с безобразным, нравственного с безнравственным. Старший школьник проявляет нетерпение ко всякого рода фальши, неискренности и грубости. Зарождение основ нравственности начинается с раннего детства. Еще И.М. Сеченовым было отмечено, что ребенок ассоциирует свою особу «со всеми проходящими через его сознание героями и со всеми их свойствами, сначала, разумеется, чисто внешними. Эта история продолжается все время, пока представление его о рыцаре путем повторных слуховых рефлексов (рассказов) наполняется все более и более рыцарскими свойствами. Введите в состав рыцаря отвращение к пороку, и ребенок, ассоциируя себя с таким рыцарем, будет презирать порок, т.е. на основании своих представлений о физиономии порока. Заставьте вашего рыцаря помогать слабому против сильного, и ребенок делается Дон Кихотом: ему случается дрожать от волнения при мысли о беззащитности слабого. Сливая себя с любым образом, ребенок начинает любить все его свойства; а потом путем анализа любит, как говорится, только последние. Здесь вся моральная сторона человека» [4]. Несомненно, если окружение, в котором воспитывался человек, проповедовало свойства Дон Кихота, то, вырастая, индивид будет руководствоваться этими качествами как критериями своего поведения. Развивая далее эту мысль, И.М. Сеченов продолжает: «Любовь к правде, великодушие, сострадательность, бескорыстие, равно как ненависть ко всему противоположному, развиваются, конечно, тем же путем, т.е. частым повторением в сознании страстных представлений (образных или слуховых - это все равно), в которых яркая сторона изображает все перечисленные свойства. Удивительно ли после этого, что ребенок в 18 лет, с горячей любовью к правде, не увлекаемый в противоположную сторону теми мотивами, которые развиваются у большинства людей лишь в зрелые годы, готов идти из-за этой правды на муку. Ведь он знает, что его идеалы, его рыцари терпели за нее, а он не может быть не рыцарем, потому что был им с 5 до 18 лет» [4].

Резюмирую сказанное, можно утверждать, что если нравственные нормы человеком усвоены плохо, или не усвоены, то их место в качестве детерминанты поведения займут иные качества - безнравственные. В данном контексте под безнравственным понимается как социально пассивное поведение, так и противоправное, преступное. Возникает парадоксальная ситуация: безнравственность порождает такое социальное отклонение, как преступность, а преступность, в свою очередь, порождает безнравственность, бездуховность.

В настоящее время в нашем обществе, лица, сосредоточивающие в своих руках значительные материальные средства, демонстрируют уровень жизни, недоступный большинству людей. Многие, особенно молодые, начинают рассматривать этот уровень как некий желанный эталон. Демонстрация фильмов, в которых только начинающий взрослеть юноша, имеет дом, машину и все прочие блага жизни выступает как идеал ожиданий подростков и юношей. Им также хочется быть таким же успешным и иметь все эти блага и для него уже неважно, каким способом это было достигнуто.

Вместе с тем, отмечают психологи, «если примеры безнравственного поведения повторять очень часто, они превращаются в моральные установки. В итоге становится возможным оправдание бесконечного числа безнравственных действий (хамства, неуважения старших, нарушения законов и т.п.). В итоге нравы становятся воплощением «особой» морали, отвечающей духу времени. На этой почве происходит конфликт идей, порождаемый «преобразованием» духовных ценностей, извращением представлений об идеале. «Умение жить» становится нравственным кредо уже многих людей. Появляется знак равенства между законами нравственности и тем, про что говорят: «так принято», «так все делают». На этой почве расцветает безнравственность в высшем своем проявлении - преступности, которая вовлекает в свою орбиту все новых и новых молодых людей, разрушая при этом духовную основу личности, её потенциал. Организованная преступность - это результат конфликта нравственных идей с безнравственными, при явном превосходстве последних, когда имеет место падение моральных принципов».

В данной ситуации можно утверждать, что человек, имеющий высокий уровень развития духовного потенциала, способен противостоять проявлениям бездуховности, и для него всегда будет иметь место борьба за нравственную идею, духовным результатом которой станет утверждение в общественном сознании и культуре нравственных ценностей.

Хотелось бы отметить еще одну специфическую особенность процесса развития духовного потенциала личности - это длительность и непрерывность, при этом результаты его реализации могут быть отсрочены во времени. Необходимо также уточнить, что реализация духовного потенциала происходит в большей степени тогда, когда человек попадает в трудную ситуацию нравственного выбора, когда он поступает в соответствии с духовно-нравственными ценностями. При этом имеет место не только расходование духовного потенциала на преодоление нравственных барьеров, но и его накопление за счет совершения нравственных поступков. Поступок несет в себе иррациональную основу. В момент совершения поступка человек не успевает или не может осознать происходящего, им движет внутренний порыв, основанный на системе ценностей, принятых и усвоенных им и чаще всего не осознаваемых.

Духовный потенциал укрепляется за счет диссеминации или распространения определенного опыта, когда 
каждый поступок усиливает потенциальную возможность его повторения другими. Именно так формируются ожидаемые формы поведения в юношеской среде [6].

«Поступок, продиктованный возвышенными и благородными мотивами, направленный на доброе дело, заслуживает высокой моральной оценки, даже если в силу непреодолимого стечения обстоятельств его предметный результат оказался неутешительным» [3]. Например, если в результате попытки спасения человека на пожаре погибает и сам спасатель, поступок этот остается проявлением героизма, ибо непредметный духовный результат поступка заключается в демонстрации нравственного благородства и самоотверженности. «Соответственно, поступок, продиктованный злой волей, корыстным эгоистическим расчетом, направленный против человечности, будет оцениваться как тягостное и мрачное злодеяние в той степени, чем больше упорства и подлости, хитрости и изворотливости будет проявлено при его совершении и чем тяжелее окажутся социаль- ные последствия. В этом случае происходит разрушение духовного потенциала до состояния бездуховности, безнравственности и аморальности личности» [3].

Таким образом, перечисленные звенья психологического механизма реализации духовного потенциала в юношеском возрасте способствуют его накоплению, укреплению и реализации в окружающей действительности и выступают в качестве возможности духовнонравственного роста в юности.

В заключении хотелось бы сказать, что занимаясь воспитанием подрастающих поколений желательно помнить такие простые и одновременно такие емкие слова - вечные истины, которые, например, были сформулированы Старцем Глинской пустыни Порфирием: «Богатые средства воспитания должны противодействовать растлению человеческой природы - усовершенствовать её, отсекать недостатки, дурные привычки и склонности, облагораживать нравы и чувства, пробуждать и раскрывать силы духа».

ЛИТЕРАТУРА

1. абрин В.И. Ноэтический потенциал человека как перспектива антропологической психологии // Сибирский психологический журнал. 2007. № 26. C. 8-14.

2. Клочко В.Е. Методологические принципы теории психологических систем // Фиксированные формы поведения в образовании, науке и культуре. Бийск, 2000. C. 8-16.

3. Кондрашов В.А. Этика. Эстетика./ В.А. Кондрашов, Е.А. Чичина - Ростов н/Д.: Изд-во «Феникс», 1999. - 512 с.

4. Сеченов И.М. Избранные произведения. Т.1. М., 1952.

5. Трофимова Н.Б. Развитие духовно-нравственного потенциала учащихся в образовательном процессе (психолого-педагогический аспект): Монография. Воронеж: ВГПУ, 2008. 283 c.

6. Трофимова Н.Б. Структурно-содержательные компоненты, уровни и механизм развития духовного потенциала старшего школьника // Вестник Тамбовского университета. 2009. №9 (77). С. 324-331.

7. Эксклюзивное интервью с Михаем Чиксентмихайи (Д. Леонтьев, сентябрь 2005 г.) URL: http://www.positivepsychology.ru/history/interview.htm.

(c) Трофимова Наталья Борисовна (n_trofimova@mail.ru).

Журнал «Современная наука: актуальные проблемы теории и практики» 